\title{
A EaD no Brasil: sobre (des)caminhos em sua instauração
}

\section{Distance learning in Brazil: on the (mis)leadings of its introduction}

\author{
Katia Morosov Alonso ${ }^{1}$
}

\begin{abstract}
RESUMO
O maior acesso ao ensino superior no Brasil foi alvo de expressivas políticas públicas; a educação a distância também é incluída neste contexto. No ano de 2005 , foi publicado um decreto que regulamentava a oferta desta modalidade de ensino, prevendo as formas pelas quais se daria o credenciamento e a autorização de cursos. Desde então se assiste a algumas reformulações do que fora proposto, sem que seja observada uma avaliação mais aprofundada do instaurado até aqui. O presente artigo objetiva explicitar determinadas tendências e delineamentos presentes na oferta da educação a distância que indicam urgência na e para a avaliação desta política pública. Para tanto, analisa documentos emanados do Ministério da Educação, dados de Resumos Técnicos de Censos do Ensino Superior e publicações dedicadas ao tema. Daí torna-se possível evidenciar distorções e problemas no processo de instauração da educação a distância. Foram observados, sobretudo, na concentração de oferta em apenas dois cursos: evasão, idade de ingresso cada vez mais afastada do ingresso que se dá pelo ensino presencial, relações entre diferentes entes federados, financiamento indicativo de um modelo de oferta e a necessidade de profissionalização dos tutores. Diante disso, são levantados pontos a serem retomados/readequados na oferta da modalidade no sentido que, de fato, sejam cumpridos os objetivos propostos para seu desenvolvimento.
\end{abstract}

Palavras-chave: expansão do ensino superior; políticas públicas; educação a distância; avaliação.

DOI: $10.1590 / 0104-4060.38643$

1 Universidade Federal de Mato Grosso, Pró-Reitoria de Ensino e Graduação, Departamento de Ensino e Organização Escolar. Cuiabá, Mato Grosso, Brasil. Av. Fernando Corrêa da Costa, n ${ }^{\circ}$ 2.367. CEP: 78060-900. 


\begin{abstract}
The greatest access to higher education in Brazil was the target of significant public policies. Distance education is also included in this context. In 2005 a decree was published regulating this form of teaching, foreseeing the ways in which courses would be authorized and accredited. Since then, what was proposed has suffered some reformulation without a deeper evaluation of what has been established up to this point. The objective of this article is to explicit certain tendencies and designs in the present scene of distance education offer which indicate the urgent need of and for the evaluation of this public policy. For such a task, we analyze documents published by the Ministry of Education, data from Technical Summaries from Censuses of Higher Level Teaching, and publications on the subject. From these it is possible to find evidence of distortions and problems in the process of introduction of distance learning. Dropout, age of admission which is more and more distant from that of the admission that happens in the classroom learning, relationships between different federated entities, funding indicative of a supply model and the necessity of professionalizing tutors can be observed mainly in the offer concentration in only two courses. In view of all this, aspects are shown that should be resumed/reconfigured in the offer of courses in this modality, if that, in fact, the proposed objectives for its development are achieved.
\end{abstract}

Keywords: expansion of higher education; public policies; distance learning; evaluation.

\title{
Introdução
}

Desde os primeiros passos na implementação de projetos e programas de formação que se utilizam da Educação a Distância (EaD) em seu desenvolvimento, especialmente depois de regulamentação e da criação do Sistema Universidade Aberta do Brasil, e lá se vão aproximadamente dez anos, não houve proposição para que fossem analisados/avaliados os resultados da empreitada que tinha por objetivos o acesso ao ensino superior e a sua democratização. Os estudos no campo do desenvolvimento/implantação de projetos e/ou programas de EaD são, em sua maioria, conforme apontado por Alonso (2010), fragmentados, focados em experiências de uso de tecnologias da informação e comunicação - TIC - e, mais recentemente, no uso dos denominados ambientes virtuais de aprendizagem - AVA. Não há evidências até o momento de estudos/ pesquisas que amplifiquem a análise quanto aos impactos/resultados de ação 
que manifesta em sua origem uma política pública com vistas à ampliação de vagas ao ensino superior e com foco na formação de professores. Isso como possibilidade de que fossem melhorados os níveis de qualidade do ensino fundamental (BARRETO, 2012).

Em dossiês, periódicos e outros meios que divulgam pesquisas no campo educacional, é possível observar tendências na instauração da EaD no Brasil. Alonso (2010), Dourado (2008), Giolo (2010), entre outros, atentavam para o caráter quantitativista, privatista e de novos nichos de mercado relacionados à expansão do ensino superior e, como consequência, no desenvolvimento/ consolidação da EaD. Por outro lado, Peixoto (2009) e Souza (2009) discutem e problematizam o trabalho docente e a formação por meio da EaD como expressão de intensificação/desqualificação para o primeiro caso e de aligeiramento para o segundo.

Haveria, afinal, para além das tendências aqui indicadas, estudos que pudessem identificar movimentos e dinâmicas próprias da $\mathrm{EaD}$ que consubstanciassem ou indicassem o cumprimento ou não das finalidades e objetivos que regulamentaram o processo de instauração da EaD no Brasil?

São poucas as pesquisas nessa área. Pelo tempo decorrido desde as primeiras iniciativas em $\mathrm{EaD}^{2}$ e considerando, como faz Cury (2008), ser o número 10 expressivo pelos seus significados, importante seria avaliar o processo de instauração da modalidade com foco nos objetivos que a fundamentam. De toda maneira, alguns indicadores são perceptíveis no contexto da instauração da $\mathrm{EaD}$ no Brasil: concentração de cursos nas denominadas licenciaturas, especialmente na formação em Pedagogia e no bacharelado em Administração. Já no ano de 2010, os cursos de Pedagogia e Administração na graduação a distância representavam $61 \%$ das matrículas, outras $48,60 \%$ das matrículas estavam localizadas em cursos como Letras, Matemática, Ciências Biológicas, História e Ciências Ambientais. O curso de Pedagogia, que figurava em quarto lugar entre os cursos presenciais, saltou para o primeiro entre os cursos a distância, acompanhado pelo de Administração.

Essa é a tendência de expansão da $\mathrm{EaD}$ mais significativa nos últimos dez anos: alta concentração da oferta em dois cursos apenas.

Se os números apontam para determinada direção, é importante verificar ainda a disposição da oferta de cursos em EaD no país, aí também se observando um movimento indicativo de concentração por região, seguindo o que ocorre com o ensino presencial: em 2011, de um total de 817.887 matrículas em cursos de EaD, 53\% eram de alunos da região Sul, $24 \%$ da Sudeste, $14 \%$ da Centro-Oeste,

2 O decreto n. 5.622 que regulamenta o art. 80 da Lei n. 9.394, de 20 de dezembro de 1996, considerado como marco para a oferta da modalidade de $\mathrm{EaD}$, data de 19 de dezembro de 2005. 
TABELA 1 - NÚMERO DE MATRÍCULAS POR MODALIDADE DE ENSINO NOS DEZ MAIORES CURSOS DE GRADUAÇÃO - BRASIL - 2009

\begin{tabular}{llccclcc}
\hline & \multicolumn{3}{c}{ Graduação Presencial } & & \multicolumn{4}{c}{ Graduação a Distância } \\
Rank & Curso & Matrículas & \% & Rank & Curso & Matrículas & \% \\
\hline 1 & Administração & 874.076 & 17 & 1 & Pedagogia & 286.771 & 34 \\
2 & Direito & 651.600 & 13 & 2 & Administração & 228.503 & 27 \\
3 & Engenharia & 419.397 & 8,2 & 3 & Serv. Social & 68.055 & 8,1 \\
4 & Pedagogia & 287.127 & 5,6 & 4 & Letras & 49.749 & 5,9 \\
5 & Enfermagem & 235.281 & 4,6 & 5 & C. Contábeis & 29.944 & 3,6 \\
6 & C. Social & 205.409 & 4 & 6 & Matemática & 23.774 & 2,8 \\
7 & C. Contábeis & 205.330 & 4 & 7 & C. Biológicas & 19.626 & 2,3 \\
8 & Ed. Física & 163.528 & 3,2 & 8 & História & 16.864 & 2 \\
9 & Letras & 145.241 & 2,8 & 9 & C. Social & 15.802 & 1,9 \\
10 & C. Biológicas & 133.204 & 2,6 & 10 & C. Ambientais & 13.091 & 1,6 \\
& Outros & 1.795 .703 & 35 & & Outros & 85.946 & 10 \\
& Total & 5.115 .896 & 100 & & Total & 838.125 & 100 \\
\hline
\end{tabular}

FONTE: Brasil (2010).

$8 \%$ da Nordeste e apenas $1 \%$ da Norte. Há, é claro, uma razão entre população e oferta, no entanto, se a $\mathrm{EaD}$ traz em seu bojo a ideia, ou melhor, a proposta de maior flexibilização de oferta, bem como a do acesso, a distorção apontada poderia ser, ao menos, minimizada. Disso decorre ainda, e claramente, maior concentração dos polos presenciais para e no atendimento aos alunos por região: quanto mais alunos, maior o número de polos presenciais, seguindo, portanto, a mesma concentração.

Outra tendência no âmbito da EaD é apontada no Resumo Técnico do Censo da Educação Superior do ano de $2011^{3}$. Neste ano, os ingressos em cursos presenciais apresentavam média de 25 anos, sendo 18 anos a idade mais frequente. Ainda nessa modalidade, metade dos ingressantes tinha até 22 anos e os $25 \%$ com idade mais avançada tinham mais de 28 anos. Na graduação a distância, os ingressantes apresentavam, em média, 32 anos, e a idade mais frequente era de 30 anos, sendo que $25 \%$ do total possuíam mais de 37 anos. Segundo conclusões contidas nesse documento, observa-se na graduação presencial crescente movimento em que mais indivíduos na condição de ingressos têm a idade esperada. Isso, de acordo com os dados, "está relacionado, possivelmente, com a melhoria do fluxo dos estudantes nas etapas anteriores de ensino. No caso da graduação a distância, diferentemente, observa-se aumento da idade modal (de 28 anos,

3 Disponível em: < http://downloadsuperior.inep.gov.br/educacao_superior/censo_superior/ resumo_tecnico/resumo_tecnico_censo_educacao__2011.pdf $>$. Acesso em: 10 ago. 2013. 
em 2009 e 2010, para 30 anos, em 2011)" (BRASIL, 2011, p. 65). Esse dado é relevante, uma vez que, para os cursos a distância e pelo financiamento, no caso das instituições públicas por meio da Universidade Aberta do Brasil (UAB), há tempo determinado para integralização da formação e, ao mesmo, o trabalho da docência é de responsabilidade das denominadas equipes multiprofissionais e com um alunado que, necessariamente, teria de ser atendido de maneira diferenciada tanto do ponto de vista pedagógico quanto por sua inserção institucional.

Outro movimento a ser destacado é o relacionado à evasão. Conforme dados do ano de 2008, as instituições que ofertavam cursos na modalidade de EaD enfrentavam evasão de $30 \%$ ou mais de seus alunos (ABRAEAD, 2008, p. 65), de maneira que várias delas intensificaram estudos que pudessem identificar as causas para isso, corroborados pelo relatório do Censo EAD.BR/2012 da Associação Brasileira de Educação a Distância - ABED": "A evasão é um problema constante na EAD [...] as causas indicadas continuam sendo falta de tempo e não adaptação à metodologia [...] o perfil do aluno continua sendo, na maioria, do sexo feminino, com idades que variam entre 18 e 40 anos, que estudam e trabalham" (p. 127).

Entre os movimentos/dinâmicas há outro aspecto que marca, profundamente, a expansão da oferta na $\mathrm{EaD}$ : o recrutamento dos profissionais tutores. Talvez uma das características mais relevantes que assume o caso brasileiro no desenvolvimento da $\mathrm{EaD}$ seja, justamente, o contingente de tutores cuja contratação, no caso da UAB, se dá por meio do pagamento de bolsas. Para Oliveira e Lima (2013), a tutoria vem se constituindo como elemento fundamental das experiências de formação pela $\mathrm{EaD}$, assumindo responsabilidades docentes pela formação dos alunos. São vários os estudos que problematizam e discutem a tutoria na EaD (MORGADO, 2003; MILL et al., 2010), no entanto, mais e mais a atuação do tutor se destaca quando do atendimento aos alunos em cursos não presenciais, materializando um contingente profissional cujas condições de trabalho e formas de contratação são questionáveis, redundando em dúvidas crescentes sobre possíveis formalizações de serviço/profissional que, dia a dia, incorpora centralidade na docência em EaD.

Os movimentos aqui apontados, sem que se caracterize como uma avaliação mais ampla que exigiria análises bastante complexas de caráter quantitativo e qualitativo, são apresentados como importantes indicadores para se (re)pensar a EaD. Há evidências que exigiriam retomadas ou readequações dos objetivos que instauraram a oferta da EaD no Brasil. Daí a necessidade, antes mencionada, de uma avaliação que descortinasse limites e possibilidades

4 Disponível em: $<$ http://www.abed.org.br/censoead/censoEAD.BR_2012_pt.pdf $>$. Acesso em: 10 ago. 2013. 
nesse campo. Considerando então o até aqui exposto, bem como a análise que subsidiasse decisões com relação a encaminhamentos para uma avaliação, o presente trabalho tem por objetivos, com base em análise documental, trazer à cena certa dinâmica de expansão da $\mathrm{EaD}$, que tem implicado contramão frente aos objetivos propostos para a modalidade e, ao mesmo tempo, evidenciar que recomendações foram trabalhadas, desde o ano de 2005, quanto a determinadas fragilidades na instauração da oferta de vagas no ensino superior em cursos a distância. $\mathrm{O}$ trabalho aqui exposto busca então, na interseção de análises documentais e determinados resultados expressos em pesquisas e resultados, sobretudo os divulgados pelo Instituto Nacional de Estudos e Pesquisas Educacionais Anísio Teixeira - INEP -, caracterizar "caminhos" que pouco a pouco conformam e consolidam a experiência brasileira na oferta de cursos em nível superior na EaD.

\section{Reencontrando temas e propostas para a oferta da EaD}

Em consulta a documentos relacionados à implantação da EaD no Brasil, sobretudo os emanados do Ministério da Educação, é possível a análise de um deles cujo título é "Documento de Recomendações - Ações Estratégicas em Educação Superior a Distância em Âmbito Nacional"'. Este documento foi elaborado por uma comissão de especialistas designados pela Secretaria de Educação Superior - SESu - e teria por finalidade "oferecer subsídios para a formulação de ações estratégicas para a Educação a Distância (EAD) a serem implementadas nas universidades, em consonância com as políticas da Secretaria de Educação a Distância" (BRASIL, 2005, p. 1). Independentemente da comissão que o elaborou, ou das políticas propostas pela extinta Secretaria de Educação a Distância - SEED $^{6}$-, ou ainda, dos resultados que puderam ser obtidos pelas recomendações ali postas, é importante trazê-lo como marco das discussões que cercam o desenvolvimento da $\mathrm{EaD}$ em nosso país nesses últimos dez anos: o documento data de 28 de janeiro de 2005.

5 Disponível em:<http://portal.mec.gov.br/sesu/arquivos/pdf/acoes-estrategicas-ead.pdf $>$. Acesso em: 10 dez. 2013.

6 A SEED/MEC foi extinta em 2011 e seus programas e ações (Domínio Público - biblioteca virtual, DVD Escola, E-ProInfo, E-Tec Brasil, Programa Banda Larga nas Escolas, Proinfantil, ProInfo, ProInfo Integrado, TV Escola, Sistema Universidade Aberta do Brasil (UAB), Banco Internacional de Objetos Educacionais, Portal do Professor, Programa Um Computador por Aluno - Prouca, Projetor Proinfo) foram integrados a outros organismos do MEC. 
O documento mencionado é constituído por quatro temas desdobrados em considerações, derivando daí recomendações. Os temas são: Políticas e Legislação; Avaliação em EaD em três dimensões: de processo, de desempenho escolar, de desempenho docente; Educação Especial; e Tecnologias da Informação e Comunicação. Além de problematizar os temas citados, a comissão propôs encaminhamentos com o intuito de assegurar qualidade, acesso e mobilidade de estudantes e docentes entre diferentes modalidades de ensino, assim como "estimular novas ações dentro de diretrizes e princípios de qualidade" (BRASIL, 2005, p. 1).

De maneira resumida, o documento indicava:

- Políticas e Legislação: necessidade de se garantir qualidade, acesso democrático, produção científica, divulgação de resultados, seguimento das normas jurídicas para os diferentes níveis de ensino, tratamento equânime entre os sistemas presencial e a distância, tratamento diferenciado para custos de transmissão/comunicação, elaboração de regras mais claras às relações trabalhistas dos profissionais que atuam na $\mathrm{EaD}$;

- Avaliação: integração de instrumentos para credenciamento, autorização e reconhecimento de cursos, maior sintonia entre diretrizes do governo federal e a dos estados, existência de sistema online para divulgação pública: de disponibilidades, projetos, pareceres, situação de ofertas e resultados; fomento a formatos inovadores de aprendizagem com o uso das TIC, considerando flexibilidade e interação, criação de mapas topológicos que indicassem produção e desempenho das Instituições de Ensino Superior (IES) por programa, curso e instituições, além da observância de elementos como: qualidade de conteúdos, infraestrutura, arquiteturas pedagógicas, armazenamento, suporte tecnológico considerando as condições regionais e locais, fomento a pesquisa e acompanhamento da inserção social dos programas /ofertas;

- Educação Especial: criação de Centros de Referência em Educação a Distância na Educação Especial com o objetivo de: pesquisas e constituição de sistemas tecnológicos para atender a diferentes demandas nessa área, apoiar oferta de formação dos profissionais envolvidos na $\mathrm{EaD}$ com foco na educação especial, elaboração de diretrizes que subsidiassem avaliação sobre acessibilidade e avaliação institucional com base também neste último aspecto;

- Tecnologias da Informação e Comunicação: na dimensão infraestrutura que as necessidades de estruturação de sistemas tecnológicos estivessem submetidas a objetivos pedagógicos, que os elementos para consecução dos sistemas não fossem considerados como exigências de um cheklist, 
mas necessários à modelagem de um curso, daí: material de apoio online dispostos em Biblioteca Digital, caracterização de trajetórias de aprendizagem com o uso de recursos para armazenamento e análise de logs, sistemas de gerenciamento de Banco de Dados, Sistemas Tutores Inteligentes e recursos de controle e retroalimentação de aprendizagem. Para além disso, o documento propunha ação efetiva dos alunos na criação, intercâmbio e socialização de suas experiências em relação ao uso dos recursos tecnológicos, bem como a experimentação como elemento catalisador nas ações da $\mathrm{EaD}$, o que redundava em uma lista de possíveis recursos/elementos de comunicação, os quais não caberia ser trazidos no momento, para a estruturação de sistemas bastante interativos.

Ao final, a comissão dispôs tópicos que mereceriam aprofundamento: definições de "presencialidade física" e de "provas presenciais", tendo em conta as diferentes interpretações da lei maior a esse respeito (Decreto 5.622, de dezembro de 2005); contratação de parcerias considerando reutilização de material didático e terceirização comercial.

O documento em análise, passados dez anos de sua elaboração, traz elementos e aspectos que continuam em pauta, alguns agudizados, exatamente pela oferta massificante que a EaD vem admitindo, especialmente na formação de professores. Os serviços de comunicação, a criação de repositórios públicos que congregassem a produção de materiais didáticos, a consolidação de processos de ensino/aprendizagem interativos, a concretização de leis trabalhistas indicativas dos novos serviços que a $\mathrm{EaD}$ demanda nas instituições de ensino superior são alguns dos aspectos que mereceriam mais atenção e disponibilidade com vistas à superação de problemas pelos organismos responsáveis pela disseminação da EaD no Brasil: Secretaria de Educação Superior (SESu) e Coordenação de Aperfeiçoamento de Pessoal de Nível Superior/Universidade Aberta do Brasil/ Ministério da Educação (CAPES/UAB/MEC) mais especificamente.

É importante verificar que os temas e recomendações postos no documento em pauta são muito semelhantes ao que foi apontado desde a constituição da Universidade Virtual Pública do Brasil - UniRede ${ }^{7}$, consórcio criado pelas IES públicas no ano de 1999, antes do advento do Sistema UAB, até o momento em que estudos e pesquisas começam a desvendar limitações quanto à instauração de uma política pública com o escopo do qual se revestiu a implantação da $\mathrm{EaD}$ no Brasil (ALMEIDA, 2012; OLIVEIRA, 2014 entre os principais). Da mesma maneira que indica limites, a proposta sobre possibilidades de retomadas e

7 Para maiores informações, acessar: $<$ http://www.aunirede.org.br/portal/index.php?option= com_content $\&$ view $=$ article $\&$ id $=43 \&$ Itemid $=27>$. 
composição de ações que redirecionassem e resignificassem a oferta da EaD é um passo importante no sentido de tratar a expansão por meio da modalidade, qualificando todo o investimento de recursos financeiros, humanos e pedagógicos nesse campo. Há um "instituído" que vem conformando a oferta da $\mathrm{EaD}$ que, neste trabalho, é entendido como visceral para reencaminhamentos dessa oferta. Compreendendo, como Libâneo, Oliveira e Toschi (2010), o "instituído" como as normas legais vigentes para a organização da estrutura educacional determinada pelos órgãos oficiais, há que se acrescentar que, no caso da $\mathrm{EaD}$, outro instituído se põe no processo de instauração da oferta pela modalidade: a forma pela qual se dá o financiamento de cursos por meio do Sistema UAB. É nas e pelas planilhas financeiras que se configuram determinados modos de organização da formação: professores conteudistas, formadores, tutores, coordenações, serviços a serem contratados e estabelecimento de valores, entre os principais elementos ali prognosticados, são previstos e adequados ao número de alunos a serem atendidos pelas instituições públicas de ensino superior. No contexto da EaD, mais do que os decretos que a regulamentam ou dos Referenciais de Qualidade para sua consecução, o "instituído" impõe-se pelo financiamento, com consequência visível na e para a oferta da modalidade. Entre recomendações como as antes verificadas e o instaurado na oferta da $\mathrm{EaD}$, é possível vislumbrar determinados delineamentos em que se insinuam problemáticas a serem discutidas/debatidas para uma avaliação do desenvolvimento da EaD. A primeira delas, sem dúvida, é a forma pela qual se faz o financiamento da oferta; outra é a profissionalização dos tutores, e uma terceira é a da concentração da oferta em determinados cursos. Estes apontamentos são tidos como emergenciais e necessários de serem trabalhados rapidamente, vistas as distorções crescentes sobre a oferta da $\mathrm{EaD}$, levando a um reforço dos pré-conceitos e à censura da modalidade como alternativa de formação. Isso tem levado, como argumenta Alonso (2010), ao não reconhecimento de que a $\mathrm{EaD}$ é parte integrante, em primeiro lugar, de uma política de expansão do ensino superior como um todo e, em segundo, pela sua visibilidade tendo em conta a constituição dos polos presenciais. É por essa "ponta" que, na maior parte das vezes, se faz a "leitura" da oferta da EaD, disseminando-se, como apontado por Lemgruber (2010), a ideia de repassadores de "pacotes" instrucionais.

A otimização do uso de recursos humanos, financeiros, a democratização do acesso ao ensino superior, bem como cuidar da qualidade dessa expansão, são requisitos capitais no sentido de efetivar a EaD como possibilidade concreta e alternativa de formação relevante para os que buscam formação em nível superior. Portanto, os delineamentos que vão conformando essa oferta necessitam ser explorados e revisitados, como se verá a seguir. 


\section{Observações sobre o instaurado em EaD}

Entre propostas e efetivação de caminhos e encaminhamentos no campo da $\mathrm{EaD}$, há conclusões possíveis de serem verificadas: sobre os modelos que se concretizaram no espaço de dez anos de oferta da modalidade; da tutoria como função docente e das áreas em que a expansão se deu.

No primeiro caso, seguindo o estudo de Faria, Lima e Toschi (2013), as organizações institucionais influenciariam o dia a dia didático de cursos a distância. A organização de equipes, materiais didáticos, relação professor-aluno e oferta de cursos estariam intimamente ligados à organização e à abordagem das práticas de EaD. Para as autoras, houve na implementação, particularmente do Sistema UAB, uma indução de que, por um lado, supriram-se dificuldades para o consórcio de instituições para oferta da $\mathrm{EaD}$, mas dificultou-se, por outro, a oferta de cursos justamente pela associação entre instituições/entidades que, do ponto de vista das responsabilidades constitucionais como as previstas pela LDB 9394/1996, não contam com vocação tampouco destinação orçamentária para prover o ensino superior, como é o caso dos municípios e dos estados. Outro agravante a este tipo de associação entre entidades com vocações diferenciadas refere-se "à volatilidade de gestores, ou seja, a troca de prefeitos e governadores" (p. 29), influenciando, por exemplo, na reprovação dos polos e na suspensão da oferta de cursos nesses espaços pela IES.

Dessa forma, a organização da EaD nas IES públicas como instituições comfinalidade dupla, de cursos dual mode e associadas se caracterizam como umpadrão induzido pela política pública da UAB e pode estar encontrandodificuldades (ALONSO, 2010; SEGENREICH, 2009) justamente pelo tipo deassociação que se estabelece e a descentralização da responsabilização dos polos para os entes federados sem vocação para o ensino superior [...] Além disso, é preciso estar atento para a estandardização dos cursos [...] Asinterações mais cosmopolitas (FEENBERG, 2001) exigem uma visão mais pós-fordista e de abertura para novas realidades. É possível que, apesar desta forte indução de modelos, abordagens e organização nas universidades públicas brasileiras, as próprias IES, a partir das experiências que realizam edas dificuldades que vivenciam, projetem novos modelos, abordagens eformas de gestão, devido ao amadurecimento gerencial que passam a vivenciar e que lhes possibilite criar autonomamente o modelo de EaD que julguem o mais adequado às suas necessidades. Porém, é preciso mudançasnos processos de financiamento que, no Sistema UAB ainda é 
forte indutor dos modelos analisados. Autonomia financeira e gerencial dos cursos a distância nas universidades públicas são ainda uma questão séria a se desenvolver nas políticas públicas educacionais de fomento à EaD (FARIA; LIMA; TOSCHI, 2013, p. 29-30).

Pelo aqui exposto, o enfrentamento às formas de financiamento e, por consequência, ao instituído por meio dele, seria um dos aspectos fundamentais no sentido de readequação de políticas para o desenvolvimento da $\mathrm{EaD}$. Uma melhor sintonia entre os entes federados, bem como a possibilidade de experimentações por parte das IES seriam encaminhamentos bem-vindos.

Com relação à tutoria, prosseguindo com o segundo elemento, cogente efetiva tomada de decisão pelos organismos que financiam/regulam a oferta da EaD, pesquisas recentes (OLIVEIRA, 2014; MILL, 2012), com levantamento bastante amplo sobre as funções dos denominados tutores, evidenciam que esses profissionais exercem atividades de natureza docente. Por mais que se queira admitir outras responsabilidades que não aquelas do ensinar e aprender, do acompanhamento dos alunos e da participação nos processos de avaliação, entre as principais, a função de um tutor está intimamente ligada ao desenvolvimento da formação em sentido amplo. $\mathrm{O}$ tangenciamento à discussão sobre $\mathrm{a}$ tutoria e docência tem negligenciado defesa substanciada do reconhecimento do tutor como um professor no âmbito das políticas públicas no Brasil, ainda que seu exercício profissional se dê de forma coletiva ou compartilhada. Conforme Oliveira (2014), tanto nos documentos da UAB quanto nos das IES, há ausência de definições sobre a natureza dos serviços dos tutores; a pesquisadora reputa tal ausência à incompreensão e à negação de aproximação do labor tutorial à docência. Decorrentes disso haveria, pois, lacunas significativas ao se pensar a profissionalização do tutor tanto no âmbito do que se realiza junto ao alunado quanto do ponto de vista das relações trabalhistas.

Assumir a discussão sobre a profissionalização do tutor insinua duas dimensões de seu fazer: definição clara sobre a natureza do seu trabalho de modo que se constitua daí uma identidade profissional e, por outro lado, o seu reconhecimento como profissional que se insere e participa dos cotidianos institucionais. O não enfrentamento da questão da profissionalização do tutor implicará, sem dúvida, como vem ocorrendo, a precarização do trabalho dos envolvidos com a docência na EaD e da qualidade da formação dos alunos que, por várias razões, optaram por cursos ofertados nessa modalidade de ensino.

Outro problema no desenvolvimento da EaD é o da concentração da oferta em determinadas áreas da formação e a necessidade de sua diversificação. Como apontado anteriormente, a concentração de cursos em Pedagogia e 
Administração, por mais que o discurso oficial atente para áreas prioritárias do serviço público, por exemplo, é indicativo de enorme distorção. Especialmente para o curso de Pedagogia, que tem atualmente mais alunos matriculados na modalidade de EaD do que no ensino presencial. Essa "virada" ocorreu no ano de 2009, sendo que, pelos dados do INEP, naquele ano, dos 118.376 alunos que concluíram o curso de Pedagogia, 55\% graduaram-se por EaD, contra $45 \%$ que o fizeram pela educação presencial. $\mathrm{O}$ dado inédito confirmou tendência já evidenciada na série histórica iniciada em 2005. De maneira análoga, observa-se a mesma tendência com relação às licenciaturas: em números absolutos, o ensino presencial responde pela maioria dos matriculados, mas, em termos percentuais, a EaD cresce mais. "Entre 2000 e 2009, licenciaturas nesse segmento saíram de 1.682 matrículas para 427.730. No presencial, foram de 836.154 para 978.061. Expansão entre 2000 e 2004 e retração de 2005 a 2009" (A VIRADA..., 2011, p. 1). Absolutamente se trata de dado secundário, pois a conformação que se expressa na oferta da EaD é a de cursos de licenciaturas como "nicho" na e para a modalidade e de outros para a educação presencial. O fosso que se cria entre as modalidades é abissal, fazendo com que se reconheça certos campos do conhecimento como mais afeitos à oferta de EaD que outros (ALMEIDA, 2012).

O que se observa, ao menos com os dados aqui expostos, são mesclas de delineamentos e problemáticas de diferentes ordens e natureza: de formas de financiamento e relação entre entes federados, de significar profissionalização para o contingente de tutores e diversificação de oferta que implique melhor distribuição, portanto, experimentação e estruturação de infraestrutura que sustente a formação para além das licenciaturas, especialmente do curso de Pedagogia.

Por se tratar de política pública endossada por um aporte de recursos financeiros substantivos (seriam, entre os anos de 2006 a 2012, aproximadamente $\mathrm{R} \$$ 3.618.670.135 disponibilizados ao Sistema $\mathrm{UAB}^{8}$ ), as problemáticas que se inserem no contexto da oferta e expansão do ensino superior denotam novos campos e direções cada vez mais complexos. Justamente por não se tratar de feitos ordinários, à medida que esse movimento tem por base a formação que se diferencia pelo atravessamento do uso mais intenso das TIC ou de reorganizações e relações institucionais diferenciadas, apenas como exemplo, constrange as tomadas de decisões relevantes na e para a oferta de cursos na modalidade de $\mathrm{EaD}$, flagrando, portanto, a urgência para que essa política seja avaliada e repensada considerando o até aqui instaurado. Não é salutar, tampouco prudente, deixar que, por inércia, tendências e movimentos como os delineados no presente trabalho sejam ignorados. Como assinalado por Oliveira (2014), muito do

8 Disponível em: <http://www.cee.ce.gov.br/phocadownload/apresentacoes/ apresentao\% 20uab\% 20 fortaleza\%202013-06-03.pdf>. Acesso em: 15 fev. 2014. 
reforço de pré-conceitos relacionados à oferta da $\mathrm{EaD}$ no ensino superior tem estreita relação com a maneira pela qual se dá sua instauração, daí a avaliação do instaurado como imperativo para a reorganização e a readequação desta oferta.

\section{Rascunhando possibilidades}

Longe de perceber a EaD como um campo ou elemento descolado de movimentos mais vastos na expansão do ensino superior no Brasil, mas reconhecendo que determinadas tendências e dinâmicas vão se consolidando num determinado período de tempo, a pretensão aqui foi a de esboçar problemáticas, chamar a atenção para uma avaliação que reconsidere aspectos e elementos quando da instauração de uma política pública específica. Com os contornos antes indicados e considerando a existência de documentos emanados do próprio MEC, é fatível apontar três âmbitos relevantes para o debate/reconsiderações na oferta da EaD coincidentes com alguns dos apontados na segunda seção do presente trabalho: o da legislação que a regula; do uso das TIC; e o da institucionalização da modalidade.

De modo bastante pontual, aquilo que se refere à legislação tem como principais alvos: a redefinição dos instrumentos de credenciamento/autorização da oferta, com revisão aprofundada dos "Referenciais de Qualidade para o Ensino Superior a Distância"; a definição clara das relações entre os entes federados com vistas ao financiamento do ensino superior; a divulgação de resultados, sobretudo, os relacionados ao alcance e disponibilidades pedagógicas do já realizado; o tratamento diferenciado para custos de transmissão/comunicação; o estabelecimento de regras claras para as relações trabalhistas dos profissionais que atuam na $\mathrm{EaD}$ com destaque para a denominada tutoria.

Sobre o uso das TIC: existência de sistema online para divulgação pública: de disponibilidades, projetos, pareceres, situação de ofertas e resultados; fomento a formatos inovadores de aprendizagem com o uso das TIC, considerando flexibilidade e interação: adequação de infraestrutura, arquiteturas pedagógicas, armazenamento, suporte tecnológico considerando as condições regionais e locais, fomento à pesquisa e acompanhamento da inserção social dos programas /ofertas; e constituição de sistemas tecnológicos para atender a diferentes demandas da educação especial, apoiando a formação dos profissionais nessa área.

Com relação à institucionalização: revisão profunda das formas de financiamento com vistas à consolidação de culturas organizacionais para integração da formação presencial e não presencial. 
Assegurar acesso com qualidade ao ensino superior é, sem dúvida, princípio fundamental na consecução de determinadas políticas públicas, da mesma maneira, avaliar com vistas a tomadas de decisão, readequações e reposicionamentos é cultura e prática relevante para o cumprimento delas. Sendo assim, é essencial que se confronte o instaurado frente ao que se preconizou como objetivos, fazendo valer direitos, responsabilidade social e transparência na discussão sobre a EaD de forma mais global, orgânica, provocando/contribuindo para a democratização da educação superior como o foi em várias outras experiências internacionais.

\section{REFERÊNCIAS}

ALMEIDA, M. E. B. et al. Educação a Distância: oferta, características e tendências dos cursos de licenciatura em Pedagogia. Fundação Victor Civita, 2012. Disponível em: <http://www.fvc.org.br/estudos-e-pesquisas/2011/relatoriofinal.pdf $>$. Acesso em: 10 nov. 2013.

ALONSO, K. M. A Expansão do Ensino Superior no Brasil e a EaD: Dinâmicas e Lugares. Educação \& Sociedade, Campinas, v. 31, n. 113, p. 1319-1335, out./dez. 2010.

ANUÁRIO Brasileiro Estatístico de Educação Aberta e a Distância - ABRAEAD. Coordenação: Fábio Sanchez. 4. ed. São Paulo: Instituto Monitor, 2008.

ASSOCIAÇÃO BRASILEIRA DE EDUCAÇÃO A DISTANCIA - ABED. Censo EAD.BR.ABED/2012. Disponível em: <http://www.abed.org.br/censoead/censoEAD. BR_2012_pt.pdf>. Acesso em: 10 ago. 2013.

A VIRADA na formação. Revista Educação. Ed. 175-11, 2011. Disponível em: <http:// revistaeducacao.uol.com.br/textos/172/artigo234993-1.asp>. Acesso em: 03 abr. 2013.

BARRETO, R. G. A recontextualização das tecnologias da informação e da comunicação na formação e no trabalho docente. Educação \& Sociedade, Campinas, v. 33, n. 121, p. 985-1002, out./dez. 2012.

BRASIL. Secretaria de Educação Superior - SESu. Documento de Recomendações "Ações Estratégicas em Educação Superior a Distância em Ámbito Nacional". Brasília, 28 de janeiro de 2005. Disponível em: <http://portal.mec.gov.br/sesu/arquivos/pdf/ acoes-estrategicas-ead.pdf>. Acesso em: 10 dez. 2013.

BRASIL. Secretaria de Educação a Distância. Grupo de Trabalho EAD no Ensino Superior - GTEADES/MEC/SESU. Brasília, 28 de janeiro de 2005. Disponível em: $<$ http://portal.mec.gov.br/ sesu/ arquivos/pdf/acoes-estrategicas-ead.pdf $>$. Acesso em: 10 dez. 2013. 
BRASIL. Instituto Nacional de Estudos e Pesquisas Educacionais Anísio Teixeira (INEP). Censo da educação Superior de 2010. Resumo Técnico. Disponível em: $<$ http://download. inep.gov.br/educacao_superior/censo_superior/resumo_tecnico/resumo_tecnico_censo_educacao_superior_2010.pdf $>$. Acesso em: 10 ago. 2013.

BRASIL. Censo da educação Superior de 2011. Resumo Técnico. Disponível em: <http:// download.inep.gov.br/educacao_superior/censo_superior/resumo_tecnico/resumo_tecnico_censo_educacao_superior_2011.pdf $>$. Acesso em: 10 ago. 2013.

CURY, C. R. J. Educação no Brasil: 10 anos pós-LDB. 2008. Disponível em: <http:// www.oei.es/pdf2/educacao-superior-brasil-10-anos.pdf $>$. Acesso em: 02 out. 2013.

DOURADO, L. F. Políticas e Gestão da Educação Superior a Distância: novos marcos regulatórios? Educação \& Sociedade, Campinas, v. 29, n. 104 - Especial, p. 891-917, out. 2008.

FARIA, J. G; LIMA, D. C. B. P.; TOSCHI, M. S. Política Pública de EaD no Brasil: reflexões sobre abordagens, modelos e organização. In: ALONSO, K. M.; ROCHA, S. de A. (Orgs). Políticas Públicas, Tecnologias e Docência: educação a distância e formação do professor. EBOOK. Cuiabá, MT, EDufmt/Central de Texto, 2013. Disponível em: <http:// www.editora.ufmt.br/index.php?route= product/product $\&$ path $=68 \&$ product $\_$id $=325>$. Acesso em: 10 mar. 2014.

GIOLO, J. Educação a Distância: tensões entre o público e privado. Educação \& Sociedade, Campinas, v. 31, n. 113, p. 1271-1298, out./dez. 2010.

LEMGRUBER, M. S. Educação a Distância: para além dos caixas eletrônicos. Conferência Nacional de Educação Básica - Eixo 3. Brasília: MEC, 2010. Disponível em: $<$ http://portal.mec.gov.br/arquivos/conferencia / documentos/marcio_lemgruber. pdf >. Acesso em: 10/12/2013.

LIBÂNEO, J. C.; OLIVEIRA, J. F.; TOSCHI, M. S. Educação escolar: políticas, estrutura e organização. 9. ed. São Paulo: Cortez, 2010.

MANCEBO, D. Trabalho Docente e Tecnologias: controle e mercadorização do conhecimento. In: GARCIA, D. M. F. (Org.). Formação e Profissão Docente em Tempos Digitais. Campinas, SP: Editora Alínea, 2009. p. 199-216.

MILL, D. Docência Virtual: uma visão crítica. Campinas: Papirus, 2012.

MILL, D. et al. $O$ desafio de uma interação de qualidade na educação a distância: o tutor e sua importância nesse processo. 2010. Disponível em: $<$ http://www.diaadis. pr. gov.br/ead/modules/mydownloads_01/viewcat.php?=7>. Acesso em: 22 jan. 2011.

MORGADO, L. Os novos desafios do tutor a distância: o regresso ao paradigma da sala de aula. Revista Discursos, n. 1, Série Perspectivas em Educação, p. 77-89, dez. 2003.

OLIVEIRA, F. P. M. O Tutor nos Cursos de Pedagogia da Universidade Aberta do Brasil: características da tutoria e aspectos da profissionalização. Tese (Doutorado em Educação) - Faculdade de Ciências e Tecnologia/UNESP. Presidente Prudente, 2014. 
OLIVEIRA, F. P. M.: LIMA, C. Maria. O Tutor dos Cursos de Pedagogia das Instituições de Ensino Superior Parceiras da Universidade Aberta do Brasil: aspectos da profissionalização. ESUD 2013 - X Congresso Brasileiro de Ensino Superior a Distância, Belém/PA, 11-13/06/2013 - UNIREDE. Disponível em: <http://www.aedi.ufpa.br/esud/ trabalhos/oral/AT2/114154.pdf > . Acesso em: 08 dez. 2013.

PEIXOTO, Joana. A concepção de dispositivos pedagógicos que integrem as TIC. Inter-Ação, Goiânia, UFG, v. 34, n. 1, p. 89-104, jan./jun. 2009.

SISTEMA UAB. Fórum Nacional dos Conselhos Estaduais de Educação. Fortaleza/CE, 03/06/2013. Disponível em: <http://www.cee.ce.gov.br/phocadownload/apresentacoes/ apresentao\%20uab\%20fortaleza\%202013-06-03.pdf>. Acesso em: 15 fev. 2014.

SOUZA, A. N. As formas atuais de modernização do trabalho de professores: individualização e precarização? In: GARCIA, D. M. F. (Org.). Formação e profissão docente em tempos digitais. Campinas, SP: Alínea, 2009. p. 91-116.

Texto recebido em 21 de novembro de 2014. Texto aprovado em 04 de dezembro de 2014. 